\title{
Socioeconomic Status and Dehumanization in India: Elaboration of the Stereotype Content Model in a Non-WEIRD Sample
}

Social Psychological and

Personality Science

$1-12$

(C) The Author(s) 2020 (c) (i) (S)

Article reuse guidelines: sagepub.com/journals-permissions DOI: $10.1177 / 1948550620976206$ journals.sagepub.com/home/spp

(S)SAGE

\author{
Priyanka Khatry ${ }^{1, *} \oplus$, Kunalan Manokara ${ }^{2, *} \oplus$, and Lasana T. Harris'
}

\begin{abstract}
A perceiver's socioeconomic status (SES) should influence social perceptions toward others. However, there is little evidence for this effect within and beyond Western samples. We hence evaluate the relationship between perceiver SES and dehumanized perception in a society where status is historically defined: India. Across two studies, we hypothesized that perceiver SES would predict dehumanization toward societal outcasts - beggars - and norm violators. Replicating previous work, in Study I, upper SES perceivers dehumanized beggars more than lower SES perceivers; accounted for by low self-reported contact likelihood. In Study 2 , norm violators were perceived as less human but more so by lower rather than upper SES perceivers. This novel finding was partially explained by perceivers viewing female violators as less prototypical, aligned with theorizing in gender research. Our results indicate that SES influences dehumanization via contact likelihood as well as the perceived normativity of a targets' behavior.
\end{abstract}

\section{Keywords}

dehumanization, socioeconomic status, contact hypothesis, norm violation, India

Dehumanization occurs when human attributes, such as capacities to think and feel, are denied to a person or group (Gray et al., 2007; Haslam \& Loughnan, 2014). The stereotype content model (SCM) suggests that dehumanization is facilitated by survival pressure (Fiske et al., 2007; Harris \& Fiske, 2011). To determine whether social targets are threats or allies, perceivers make quick assessments about warmth (good vs. ill intentions) and competence (ability to act on intentions). This model then posits that targets perceived as low on warmth and competence (e.g., people who are homeless or beggars) are dehumanized, as evidenced by reduced brain activity in the social cognition brain network (Harris \& Fiske 2006, 2011; Krendl et al., 2006, 2009).

Research on the SCM postulates that dehumanization occurs in a variety of intergroup contexts, including crosssocioeconomic status (SES) interactions (Fiske, 2013). In societies with high-income inequality, SES is more than just a group categorizer; it shapes shared social norms within SES groups and determines contact likelihood across groups (Kraus \& Stephens, 2012). As such, the influence of SES on dehumanized perception may extend to the perceiver and the target; the SES of both parties should affect dehumanized perception. However, research within and beyond WEIRD (westernised, educated, industrialised, rich and democratic; see Henrich et al., 2010) samples is yet to systematically account for the influence of perceiver SES on dehumanization. We address this gap by examining whether contact likelihood mitigates, and social norm violation exacerbates, dehumanization toward traditionally dehumanized targets. We examine this in a country where class boundaries are salient and historically defined: India.

\section{SES and Dehumanization}

In societies with high inequality and limited social mobility, income, occupation, and education vis-à-vis others are key indicators of SES (Fine et al., 2019; Iversen et al., 2017; Kraus $\&$ Stephens, 2012). SES determines the neighborhoods people occupy, their social interactions, and the customs they adhere to (Adler et al., 1994; Bourdieu, 1984; Kraus \& Stephens, 2012). Research also documents greater social affiliation between same-class compared to cross-class interaction

\footnotetext{
' Department of Experimental Psychology, University College London, United Kingdom

${ }^{2}$ Department of Social Psychology, University of Amsterdam, the Netherlands * Both authors contributed equally to this work.

Corresponding Authors:

Priyanka Khatry, Department of Experimental Psychology, University College London, London WCIE 6BT, United Kingdom; Kunalan Manokara, University of Amsterdam, the Netherlands.

Email: priyanka.khatry@uclmail.net; k.manokara@uva.nl
} 
partners (Côté et al., 2017). Additionally, low-SES people are more socially engaged and act more pro-socially toward strangers, owing to their dependence on social networks for survival (Kraus et al., 2012; Piff et al., 2010). In contrast, upper SES people demonstrate increased self-focused social cognition, unethical behavior, and objectification of targets (Piff et al., 2012; Wang \& Krumhuber, 2017).

In relating SES to dehumanization, the SCM implies that competition for limited resources triggers biased perceptions (Cuddy et al., 2008). Upper SES out-groups tend to have greater social power and dominion over resources and are thus perceived as high competence but low warmth (Fiske, 2013). Alternatively, lower SES out-groups are viewed as a strain on collective resources (e.g., dependence on social welfare) and are hence deemed low on warmth and competence (Fiske et al., 2002). Across cultures, lower SES groups are often ascribed animalistic traits, while upper SES groups are described as mechanistic (Loughnan et al., 2014; Sainz et al., 2019). As outlined above, research thus far has evaluated the influence of target SES on dehumanization; here, we focus on the influence of perceiver SES.

\section{Psychological Mechanisms: Contact and Norm Violation}

The contact hypothesis proposes that interpersonal contact between members from varied groups increases familiarity and decreases intergroup hostility (Allport, 1954). Reduced intergroup prejudice is achieved when the following optimal conditions are bundled: equal status between groups, common goals, intergroup cooperation, and institutional support (Allport, 1954; Pettigrew $\&$ Tropp, 2006). In the context of cross-SES interactions, we expect societal outcasts (e.g., beggars) to be the most dehumanized by group members they are least likely to interact with: upper SES people. Thus, by taking perceiver SES into account, we attempt to replicate and elaborate on previous work detailing the dehumanization of outcasts (Harris \& Fiske, 2006, 2007, 2009).

Social norm violations infringe upon behaviors deemed acceptable by a group (Cialdini \& Trost, 1998; Kurzban \& Leary, 2001; Van Kleef et al., 2011). Violators are often perceived as a threat to the maintenance of the status quo (Stamkou et al., 2016; Williams, 1997). Witnessing social norm violations triggers negative affect and punishment motives toward the violator (Bastian et al., 2011; Ohbuchi et al., 2004; Van Kleef et al., 2015). In the context of cross-SES interactions, one could expect norm violators to be viewed as social threats (Stamkou et al., 2016; Williams, 1997) and likely dehumanized (Harris, 2017). Here, we examine SES-based norm violations with regard to the relational norms of lower SES groups (Dhillon, 2015; Kraus et al., 2012; Piff et al., 2010). As a novel hypothesis, we postulate that lower (rather than higher) SES individuals will dehumanize norm violators due to the threat generated by such transgressors. Given that lower SES individuals are hypersensitive to threats that undermine economic survival (Gallo \& Matthews, 2003), norm violators should be dehumanized for breaking rules of prosociality that are expected in lower SES contexts (Dhillon, 2015; Kraus et al., 2012; Piff et al., 2010).

\section{Present Research}

In selecting an appropriate cultural context, we chose India: a country that has divided people into inheritable hierarchal occupational groups (castes) since $1000 \mathrm{BC}$ (Freitas, 2006). Despite its abolition, the caste system persists as identity-based group networks, determining access to resources and social mobility (Mosse, 2019). Owing to continued discrimination, lower caste individuals tend to hold menial jobs and occupy the bottom rung of SES (United Nations [UN], 2016), while higher caste individuals are more likely to hold high-status jobs, indicative of upper SES (Montaut, 2010; Mosse, 2019; NFHS-4, 2017). These historically rooted divides in Indian society offer the ideal social ecosystem to study the influence of perceiver SES on dehumanization.

In the present research, we address two questions. We first examine whether societal outcasts (beggars) would be dehumanized most by people with whom they have the least contact likelihood (Study 1); replicating and elaborating on past dehumanization work (Harris \& Fiske, 2006). We next evaluate whether violating SES-based prosociality norms would predict dehumanized perception (Study 2). We expect that lower SES perceivers are more likely to dehumanize a norm-violating target relative to upper SES perceivers due to threat (Gallo \& Matthews, 2003), a novel hypothesis.

\section{Ethics Statement}

Ethical approval for both studies was obtained from a British university. Fully anonymized data files, and accompanying output, will be made available via the open science framework.

\section{Study I}

To examine the influence of contact likelihood on the dehumanized perception of societal outcasts, we collected data from a populous city in India where beggars are a common sight: Mumbai.

\section{Method \\ Participants}

To achieve a representative sample of SES groups, we collected data in the lingua franca of the area: Hindi and English. Participants were also given the option of completing the survey either via reading $(63.8 \%)$ or listening to the experimenter (36.2\%). ${ }^{1}$ A final sample of 233 participants was recruited from Mumbai (55.4\% male, $44.6 \%$ female), ranging from 17 to 72 years old $\left(M_{\text {age }}=34.1, S D_{\text {age }}=12.4\right)$. We a priori decided to collect at least 150 participants-50 participants per SES group, using an established rule of thumb (see Nelson et al., 2018) - but due to snowballing, we oversampled. Sensitivity analyses using G*Power Version 3.1.9 (Faul et al., 2009) indicated our sample size to be sufficiently powered at $80 \%$ for detecting medium-sized between-subject effects in analysis of variance (ANOVA) models (Cohen's $f=.20$ ). 


\section{Materials and Procedure}

We presented participants with the photograph of a male beggar and, for stimuli generalizability, randomly showed one of two photographs. Measures of dehumanized perception using the 15-item human attributes inventory followed (Harris \& Fiske, 2011; e.g., how friendly, how warm). For full materials, see Supplement A.

Participants then responded to two items measuring contact likelihood toward the beggar, based on the behavioral norms of social distancing toward untouchables in the caste system (Dasgupta \& Pal, 2018; UN, 2016): "What is the likelihood you would have an interaction with this person?" and "I would go out of my way to avoid interacting with this person (reverse coded)." Items satisfactorily correlated ( $r=.32, p<.001$, $95 \%$ confidence interval $[\mathrm{CI}]=[.20, .43])$. All items were measured on 5 -point Likert-type scales $(1=$ not at all; $5=$ extremely). ${ }^{2}$

We collected self-reported SES at the end of the survey together with reports of monthly income (in rupees) and demographics, where participants identified themselves to be either lower SES $(n=69,29.9 \%)$, middle SES $(n=73,31.3 \%)$, or upper middle to upper SES $(n=91,39.1 \%)$.

\section{Results}

\section{Preliminary Analyses}

SES groups. We first examined whether SES groups would differ on reported income. ${ }^{3} \mathrm{We}$ conducted a nonparametric Kruskal-Wallis one-way ANOVA, with SES as the predictor and $\log$-transformed income as the outcome variable. SES groups significantly differed on reported income, $\chi^{2}(2)=66.81, p<.001$, $\epsilon^{2}=.32$. Pairwise comparisons revealed that lower SES individuals $\left(M_{\text {raw }}=10,489\right)$ reported having less income than middle-SES $\left(M_{\text {raw }}=37,350 ; W=8.44 ; p<.001\right)$ and upper SES individuals $\left(M_{\text {raw }}=118,197 ; W=10.04 ; p<.001\right)$. This provides evidence that self-reported SES may be reflective of one's objective financial situation in India, unlike in Western societies where these measures do not always correlate or may be driven by self-management concerns. We acknowledge that neither measure takes education into account to better estimate social class (see Cohen et al., 2017). Nonetheless, we rely on self-reported SES rather than income as an index of SES throughout.

Human attributes inventory. We conducted exploratory factor analyses (EFAs) by submitting the scale to principal axis factoring with varimax rotation. We extracted five factors; however, an examination of the Scree plot revealed a two-factor solution accounting for $44.5 \%$ variance explained. Consistent with established dehumanization frameworks (Gray et al., 2007; Harris \& Fiske, 2011; Haslam, 2006), we grouped two of the original five factors into affective attributes (e.g., warmth) and the remaining three into cognitive attributes (e.g., competence). We next conducted identical EFAs per dimension to examine item loadings within each dimension (see Supplement A for factor loadings).
Table I. Means (and Standard Deviations) of Human Attributes and Contact Likelihood.

\begin{tabular}{llll}
\hline Dependent Variables & Upper SES & Middle SES & Lower SES \\
\hline Affective attributes & $2.84(0.7 I)$ & $2.85(0.97)$ & $2.67(0.74)$ \\
Cognitive attributes & $2.53(0.64)$ & $2.57(0.69)$ & $2.87(0.67)$ \\
Contact likelihood & $2.54(I .06)$ & $3.19(I . I 4)$ & $3.09(I . I 8)$ \\
\hline
\end{tabular}

Note. SES = socioeconomic status.

\section{Central Findings}

We conducted three separate one-way ANOVAs: one for each dimension of human attributes and one for contact likelihood. We entered SES as an ordinal predictor in each model. We again Bonferroni corrected significance thresholds to account for multiple comparisons $(p<.016)$.

Affective attributes. SES was not significantly predictive of affective attributes granted to beggars, $F(2,226)=1.04$, $p=.355, \eta_{\mathrm{p}}^{2}=.009$, and none of the planned comparisons were significant (see Supplement A).

Cognitive attributes. We found that SES significantly predicted cognitive attributes, $F(2,228)=5.68, p=.004, \eta_{\mathrm{p}}^{2}=.047$ (see Table 1 for descriptive statistics). As expected, upper SES perceivers granted less mental life to beggars than did lower SES perceivers, $t(228)=3.21, p=.005, d=.517$. Middle-SES perceivers did not significantly differ from upper SES perceivers in their ratings, $t(228)=0.45, p=1.000, d=.071$, but granted less mental life to beggars than lower SES perceivers, $t(228)=2.60, p=.030, d=.430$.

Contact likelihood. SES significantly predicted contact likelihood, $F(2,230)=7.93, p<.001, \eta_{p}^{2}=.065$. As hypothesized, upper SES perceivers reported significantly less contact likelihood with beggars compared to lower SES perceivers, $t(230)=3.04, p=.008, d=.484$, and middle-SES perceivers, $t(230)=3.65, p<.001, d=.585$. Lower SES and middle-SES perceivers did not significantly differ in their contact likelihood, $t(230)=-0.53, p>.999, d=.085$.

\section{Exploring Mediation}

To test for the role of contact likelihood ${ }^{4}$ in accounting for the main effect of SES on cognitive attributes granted to beggars, we conducted mediation analyses using the GAMLj package on Jamovi (Gallucci, 2019), with 95\% CIs and 10,000 bootstrap samples. We entered SES as a difference-coded ordinal predictor (upper SES $=1$, middle and lower SES $=0$ ). We entered contact likelihood as the mediator and cognitive attributes as the outcome measure. The effect of SES on cognitive attributes became nonsignificant after including contact likelihood in the model (see Figure 1). Furthermore, a significant indirect effect of SES on cognitive attributes emerged via its relationship with contact likelihood, $b=-.06$, standard error $(S E)=.03,95 \% \mathrm{CI}$ $=[-.12,-.01], z=2.13, p=.034$. Contact hence fully 


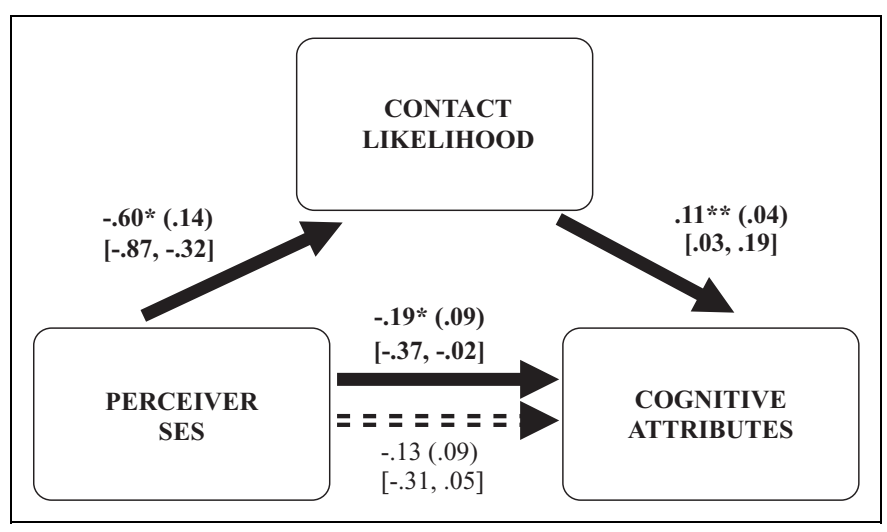

Figure I. Effect of perceiver socioeconomic status (SES) on cognitive attributes fully mediated by contact likelihood.

Note. Social class was entered as a difference-coded ordinal predictor (upper SES $=1$, middle and lower SES $=0$ ). Numbers in rounded parentheses are standard errors, numbers in square parentheses are confidence intervals. $* p<.05 . * * p<.01$.

mediated the relationship between SES and the denial of cognitive attributes to beggars.

\section{Conclusion}

Upper SES perceivers reported being less likely to interact with societal outcasts compared to their lower SES and middle-SES counterparts and thus perceived beggars as having less capacity to think. Furthermore, average dehumanization ratings were below scale midpoints even for low-SES perceivers. Our findings hence align with contact theory (Allport, 1954) and the SCM which postulates why and how people who are homeless are dehumanized (Harris \& Fiske, 2006).

\section{Study 2}

Furthering existing research on norm violation (Cialdini \& Trost, 1998; Kurzban \& Leary, 2001; Stamkou et al., 2016; Williams, 1997) and prosocial inclinations within lower SES contexts (Dhillon, 2015; Kraus et al., 2012; Piff et al., 2010), we explored how norm violations influence dehumanized perception (Harris, 2017). We postulated that the selfish nature of norm-violating behaviors (e.g., choosing not to help someone else even when the situation allows for it) should be viewed as particularly threatening by lower SES perceivers, given heightened threat sensitivity (Gallo \& Matthews, 2003) and the importance of being relationally orientated for economic survival (Kraus \& Stephens, 2012). We hence expected norm-violating targets to be perceived as less prototypical and more threatening by lower SES perceivers and, as a result, be dehumanized.

\section{Method}

\section{Participants}

We recruited 212 Indian participants ( $63.7 \%$ male, $36.3 \%$ female) with an age range of $19-65\left(M_{\text {age }}=31.27, S D_{\text {age }}=7.16\right)$ for an online study via Amazon Mechanical Turk (MTurk) and paid them US\$ 1 upon completion. Power calculations using PANGEA (Westfall, 2015) indicated our sample size to be sufficiently powered at $80 \%$, for detecting small-sized within-subject interactions in ANOVA models (Cohen's $d=.25$ ). Furthermore, sensitivity analyses with $G^{*}$ Power revealed our sample size to be adequately powered at $80 \%$, for detecting small-sized within-between interactions as well (Cohen's $f=.14$ ).

\section{Materials}

Manipulations. We employed a mixed experimental design with target gender as a between-subjects variable and target behavior and target social class as within-subject variables. Accordingly, all participants rated four vignettes. Targets were either men described to be working in an office environment or married women described to be homemakers. Each vignette described the behavior of a fictitious target, who either chose to help someone else (norm abiding) or avoided helping (norm violating). Each target description was paired with a photograph. The male target was dressed in either a suit (high SES) or casual clothing (low SES). The female target was dressed in either western clothing (more common among high-SES urban dwellers) or traditional clothing (more common among low-SES rural migrants).

Our behavior manipulation was in line with emerging evidence, where we described actions that were either appropriate or unacceptable in lower SES contexts (Butalia, 2013; Piff et al., 2010; Van Kleef et al., 2011). Our social class manipulation in the form of clothing was adapted from the study by Kraus and Mendes (2014) and consistent with theorizing about social class and clothing in India (Bhatia, 2018; Budhwar \& Varma, 2011; Dahlberg, 1996; Gelles, 2011; Kalpagam, 2008; Mount, 2017; Sandhu, 2015; Singh, 2016). We fully crossed repeated-measures stimuli, describing target behavior and target social class, and randomized presentation order (materials in Supplement B).

Human attributes. A seven-item version of the human attributes inventory (Harris \& Fiske, 2011) was used $(1=$ not at all, $7=$ extremely), which included both cognitive (e.g., how competent?) and affective (e.g., how warm?) attributes.

Dehumanized perceptions. In addition, we employed an eight-item dehumanization scale (Haslam, 2006; 1 = strongly disagree, 7 = strongly agree), which evaluated the degree to which targets were perceived as animalistic (e.g., lacked self-restraint, like an animal) and mechanistic (e.g., mechanical and cold, like a robot). We counterbalanced the order of scale presentation and randomized items.

Psychological threat. Participants rated their agreement $(1=$ strongly disagree, $7=$ strongly agree $)$ with six statements describing each target on three attributes: prototypicality (Danbold \& Huo, 2015; e.g., "this person is similar to the average Indian man/woman"), realistic threat (Stephan et al., 2000; 
Table 2. Regression Estimates of Primary Predictor and Key Manipulations (Rows) on Each Outcome Measure (Columns).

\begin{tabular}{|c|c|c|c|c|c|}
\hline $\begin{array}{l}\text { Dependent } \\
\text { Variables }\end{array}$ & Human Attributes & Human Capacities & Overt Dehumanization & Overall Threat & Prototypicality \\
\hline erceiver SES & $\begin{array}{c}b=. I 2, S E=.03 \\
95 \% C I=[.06, .19] \\
t(208)=3.65 \\
p<.001\end{array}$ & $\begin{array}{c}b=.08, S E= \\
95 \% C l=[.02 \\
t(208)=2.60 \\
p=.010\end{array}$ & $\begin{array}{c}b=.28, S E=.05 \\
95 \% C I=[.18, .39] \\
t(208)=5.27 \\
p<.00 I\end{array}$ & $\begin{array}{c}b=.25, S E= \\
95 \% C l=[.16, \\
t(208)=5.6 \\
p<.001\end{array}$ & $\begin{array}{r}b=. I I \\
95 \% C l= \\
t(207) \\
p=\end{array}$ \\
\hline $\begin{array}{l}\text { Target } \\
\text { gender }\end{array}$ & $\begin{array}{c}b=. I I, S E=.10 \\
95 \% \mathrm{Cl}=[-.09, .31] \\
t(208)=1.12 \\
p=.266\end{array}$ & $\begin{array}{c}b=.22, S E=.0 \mathrm{I} \\
95 \% \mathrm{Cl}=[.03, .4 \mathrm{I}] \\
t(208)=2.30 \\
p=.023\end{array}$ & $\begin{array}{c}b=-.49, S E=.16 \\
95 \% \mathrm{Cl}=[-.81,-.17] \\
t(208)=-2.98 \\
p=.003\end{array}$ & $\begin{array}{c}b=-.31, S E=.13 \\
95 \% \mathrm{Cl}=[-.57,-.05] \\
t(208)=-2.35 \\
p=.019\end{array}$ & $\begin{array}{c}b=.24, S E=.12 \\
95 \% \mathrm{Cl}=[.01, .47] \\
t(207)=2.06 \\
p=.04 \mathrm{I}\end{array}$ \\
\hline $\begin{array}{l}\text { Target social } \\
\text { class }\end{array}$ & $\begin{array}{c}b=-.10, S E=.05 \\
95 \% \mathrm{Cl}=[-.20, .01] \\
t(208)=-1.84 \\
p=.066\end{array}$ & $\begin{array}{c}b=-.03, S E=.06 \\
95 \% \mathrm{Cl}=[-.14, .09] \\
t(208)=-0.51 \\
p=.608\end{array}$ & $\begin{array}{c}b=-.02, S E=.05 \\
95 \% \mathrm{Cl}=[-.12, .09] \\
t(208)=-0.33 \\
p=.745\end{array}$ & $\begin{array}{c}b=-.22, S E=.06 \\
95 \% C l=[-.33,-.12] \\
t(208)=-4.08, \\
p<.001\end{array}$ & $\begin{array}{c}b=.32, S E=.07 \\
95 \% \mathrm{CI}=[.18, .46] \\
t(207)=4.50 \\
p<.00 \mathrm{I}\end{array}$ \\
\hline $\begin{array}{l}\text { Target } \\
\text { behavior }\end{array}$ & $\begin{array}{c}b=-.77, S E=.05 \\
95 \% C I=[-.88,-.67] \\
t(208)=-14.77 \\
p<.001\end{array}$ & $\begin{array}{c}b=-.89, S E=.06 \\
95 \% C l=[-.10, .78] \\
t(208)=-\mid 15.7 I \\
p<.00 I\end{array}$ & $\begin{array}{c}b=.54, S E=.05 \\
95 \% C I=[.43, .64] \\
t(208)=9.99 \\
p<.00 I\end{array}$ & $\begin{array}{c}b=.08, S E=.06 \\
95 \% \mathrm{Cl}=[-.03, .19] \\
t(208)=1.47 \\
p=.143\end{array}$ & $\begin{array}{c}b=-.53, S E=.07 \\
95 \% \mathrm{Cl}=[-.67,-.40] \\
t(207)=-7.55, \\
p<.001\end{array}$ \\
\hline
\end{tabular}

Note. SES = socioeconomic status; $S E=$ standard error; $\mathrm{Cl}=$ confidence interval. Significant values are in bold.

e.g., "this person has more economic power than they deserve"), and symbolic threat (e.g., "this person has very different values from other Indian women"). We randomized items.

\section{Procedure}

We randomly assigned participants to one of two conditions, where they viewed vignettes describing either male $(n=103)$ or female $(n=109)$ targets. For each vignette, we first measured dehumanized perceptions, followed by prototypicality and threat. Thereafter, we included a more refined measure of SES: the McArthur ladder (Adler et al., 2007), where participants rated their SES, relative to other Indians, on a 10 -point scale $(1=$ the worst off, $10=$ the best off $)$ at the end of the survey $\left(M_{\mathrm{SES}}=6.71, S D_{\mathrm{SES}}=1.54\right)$. We finally collected demographic information, together with other indices of SES such as income and class category (as in Study 1), as well as highest completed education. Participants were then debriefed and paid. ${ }^{5}$

\section{Results}

\section{Preliminary Analyses}

Self-perceptions of SES. We first examined whether self-perceptions of SES would be associated with other indices of social class: monthly income, education, and class category (main predictor in Study 1). For education, we sorted responses into the following categories $(1=$ high school graduate/vocational diploma and below, $2=$ college undergraduate, 3 = postgraduate). For class category, only one respondent reported being of a lower SES background, which is to be expected in our MTurk sample, given that computers are less accessible to lower SES respondents in India (NFHS-4, 2017). We hence created a binary index for class $(0=$ lower to middle SES, $1=$ upper middle to upper SES).

Self-reported SES was not significantly associated with education level $(r=-.03, p=.722)$. However, self-reported SES was positively predictive of log-transformed income $\left(r_{\mathrm{s}}=.15\right.$, $p=.029,95 \% \mathrm{CI}=[.13, .38])$ and binary class category $(b=.64, S E=.17, z=3.73, p<.001)$. Based on established conventions (Cohen et al., 2017), we calculated a collapsed index of wealth by aggregating income, education, and class category. SES was positively associated with this index $\left(r_{\mathrm{s}}=.23, p<.001,95 \% \mathrm{CI}=[.06, .33]\right)$, further validating our primary predictor.

Human attributes. We conducted similar EFAs to Study 1 and extracted a single dimension for each vignette $(48.94 \%$ cumulative variance explained, see Supplement B for item loadings). We therefore calculated a collapsed index of human attributes.

Dehumanized perceptions. We conducted similar EFAs, and two consistent dimensions emerged per vignette that differed in terms of item wording rather than mechanistic or animalistic dehumanization (see Supplement B for loadings). Based on item wording, we hence termed these factors human capacities ( $23.77 \%$ cumulative variance explained; e.g., this person is logical/emotional) and overt dehumanization ( $24.44 \%$ cumulative variance explained; e.g., this person is robotic/ animalistic). 
Table 3. Simple Slopes Decomposing the Interaction Effect Between Target Behavior and Perceiver SES.

\begin{tabular}{|c|c|c|c|c|c|}
\hline \multirow{2}{*}{$\begin{array}{l}\text { Dependent } \\
\text { Variables }\end{array}$} & \multirow[b]{2}{*}{$b$} & \multirow{2}{*}{$\frac{\text { Predictor }}{S E}$} & \multirow{2}{*}{$\frac{\text { Perceiver }}{t}$} & \multirow{2}{*}{$\frac{\text { SES }}{p}$} & \multirow[b]{2}{*}{$95 \% \mathrm{Cl}$} \\
\hline & & & & & \\
\hline \multicolumn{6}{|l|}{ Human attributes } \\
\hline Norm abiding & .01 & .04 & 0.31 & .758 & {$[-.06, .09]$} \\
\hline Norm violating & .23 & .04 & 6.18 & $<.001$ & {$[.16, .30]$} \\
\hline \multicolumn{6}{|l|}{ Human capacities } \\
\hline Norm abiding & -.06 & .04 & -1.62 & .105 & {$[-.13, .01]$} \\
\hline Norm violating & .22 & .04 & 6.11 & $<.001$ & {$[.15, .29]$} \\
\hline \multicolumn{6}{|c|}{ Overt dehumanization } \\
\hline Norm abiding & .36 & .06 & 6.43 & $<.001$ & {$[.25, .47]$} \\
\hline Norm violating & .20 & .06 & 3.59 & $<.001$ & {$[.09, .31]$} \\
\hline \multicolumn{6}{|l|}{ Overall threat } \\
\hline Norm abiding & .27 & .05 & 5.79 & $<.001$ & {$[.18, .37]$} \\
\hline Norm violating & .22 & .05 & 4.63 & $<.001$ & {$[.13, .31]$} \\
\hline \multicolumn{6}{|l|}{ Prototypicality } \\
\hline Norm abiding & .01 & .04 & 0.26 & .796 & {$[-.08, .10]$} \\
\hline Norm violating & .21 & .04 & 4.6 & $<.001$ & {$[.12, .30]$} \\
\hline
\end{tabular}

Note. SES = socioeconomic status; $S E=$ standard error; $\mathrm{Cl}=$ confidence interval.

Psychological threat. In similar EFAs, two factors emerged per vignette (loadings in Supplement B). Realistic and symbolic threat items clustered together (36.31\% cumulative variance explained), and a collapsed index of overall threat was calculated. Prototypicality items consistently clustered together $(17.00 \%$ cumulative variance explained) and were hence averaged.

\section{Central Findings}

We conducted five separate linear mixed-model regressions: one for each measure of dehumanization, one for overall threat, and one for prototypicality. In all models, we entered self-reported perceiver SES as an ordinal between-subject predictor and target gender (male vs. female) as a categorical between-subject factor. We entered target behavior (norm abiding vs. norm violating) and target SES (high vs. low) as within-subject factors. We Bonferroni corrected for multiple comparisons in our analyses, adjusting significance thresholds based on the number of predictors in each model $(p<.012)$. Main findings are described in text; refer to Table 2 for regression estimates and Supplement B for full results.

Human attributes. We found a main effect of behavior as predicted and a positive association between SES and humanization. These main effects were qualified by an interaction effect between behavior and perceiver SES (simple slopes reported in Table 3). The lower SES a perceiver, the greater the effect of norm violations on dehumanized perceptions (Figure 2A).

Human capacities. We found similar results for human capacities; the lower SES an individual, the greater the effect of norm violations on dehumanized perceptions (Figure 2B).
Overt dehumanization. We found similar results for overt dehumanization, where the main effect of behavior and perceiver SES were qualified by an interaction. The lower SES a perceiver, the greater the effect of norm violations on dehumanized perceptions (Figure 2C).

Prototypicality. We found similar results for prototypicality as well; the lower SES a perceiver, the greater the effect of norm violations on prototypicality (Figure 2D).

Overall threat. Perceiver SES was positively predictive of overall threat, although the interaction term between perceiver SES and behavior was nonsignificant.

\section{Exploring Mediation}

We next explored the possibility that threat and prototypicality would mediate our consistent pattern of results on dehumanization. In line with research on norm violations (Bastian et al., 2011; Ohbuchi et al., 2004; Van Kleef et al., 2015), we expected norm violators to be viewed as less prototypical and more threatening by low-SES perceivers and thus more dehumanized.

To make each of our five outcomes suitable for mediation analyses, we preprocessed them using a two-step aggregation procedure per variable. Step 1: Since target SES did not significantly influence dehumanized perceptions, these items were averaged across the two targets within each behavior condition. ${ }^{6}$ Step 2: We calculated difference scores by subtracting the means of norm-violating targets from the means of norm-abiding targets. This procedure allowed us to calculate separate indices of the extent to which manipulated behavior influenced each of the five measures.

To test for the roles of prototypicality and threat in accounting for the effect of SES on dehumanized perceptions, we conducted moderated mediation analyses using the GAMLj package on Jamovi (Gallucci, 2019). Three separate models were computed - one for each measure of dehumanization. We entered SES as an ordinal predictor, target gender as a moderator, and prototypicality and overall threat as parallel mediators, with dehumanization as the outcome measure (Figure 3 for schematic). We Bonferroni corrected for multiple comparisons in our analyses by adjusting significance thresholds based on the number of predictors in each model $(p<.012)$. Main findings are described in text (see Supplement B for full regression results).

Human attributes. The effect of SES on human attributes weakened after including prototypicality and overall threat in the model. However, overall threat was not found to be a significant mediator. A significant indirect effect of SES on human attributes emerged via its relationship with prototypicality. This indirect effect was only significant for female targets and not for male targets. Norm-violating female targets were perceived to be less prototypical and hence afforded less human 


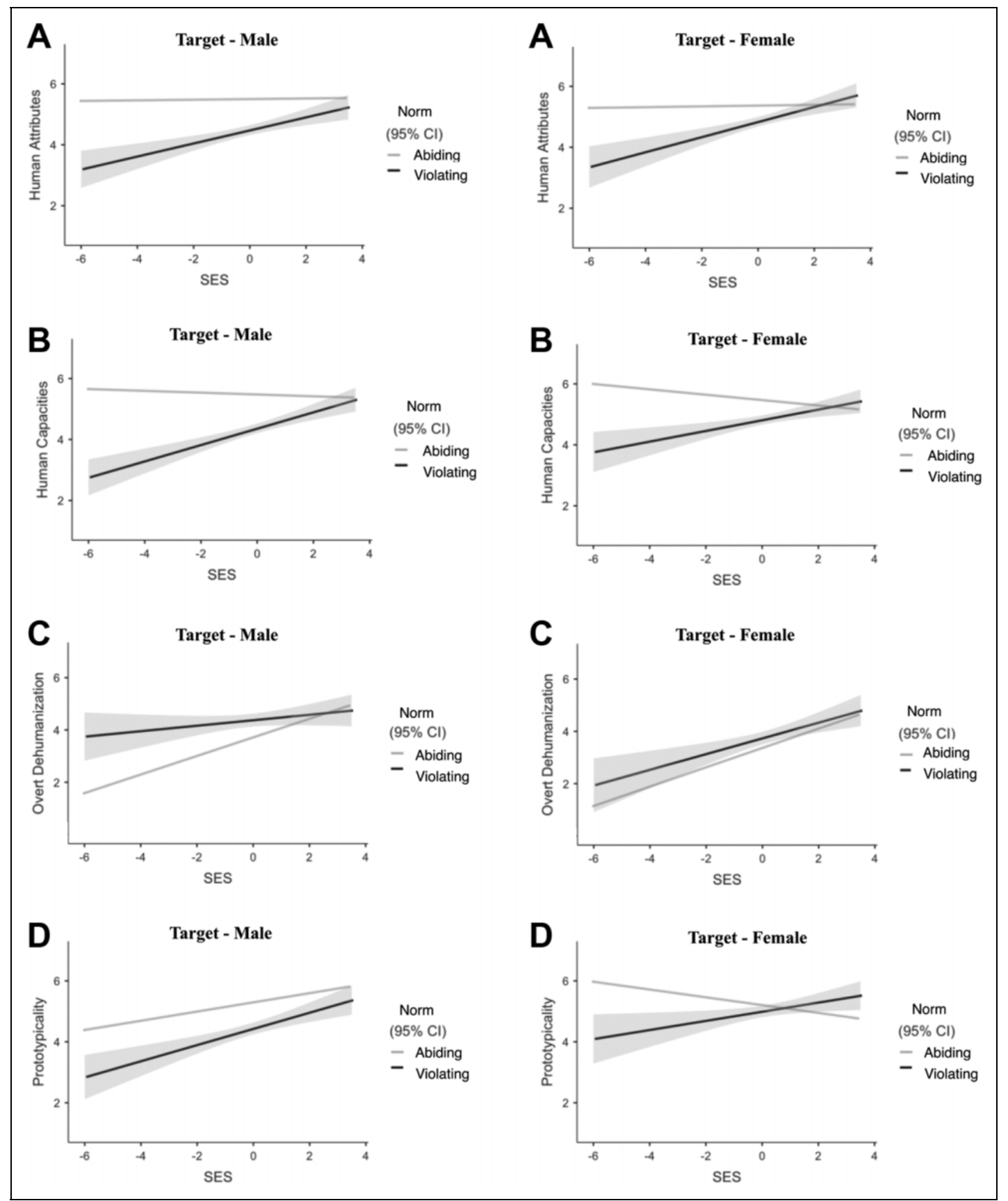

Figure 2. Joint effect of perceiver socioeconomic status and target behavior in predicting (A) human attributes, (B) human capacities, (C) overt dehumanization, and (D) prototypicality.

Note. Left panel denotes male targets, while right panel describes female targets.

attributes $(b=-.16, S E=.05,95 \% \mathrm{CI}=[-.25,-.06]$, $z=3.19, p=.001)$.

Human capacities. A similar pattern of results emerged for human capacities as well, where partial mediation via prototypicality was found only for female targets $(b=-.16, S E=.05$, $95 \% \mathrm{CI}=[-.26,-.06], z=3.19, p=.001)$.

Overt dehumanization. A similar pattern of results emerged for overt dehumanization, where prototypicality fully mediated the effect of SES-based norm violations on overt dehumanization only for female targets $(b=.10, S E=.04,95 \% \mathrm{CI}=[.02$, $.17], z=2.65, p=.008)$.

\section{Conclusion}

In line with research suggesting SES shapes relational norms and prosociality (Kraus et al., 2012; Piff et al., 2018, 2010), norm-violating targets were perceived to be less prototypical-and less worthy of humanness-by lower SES 


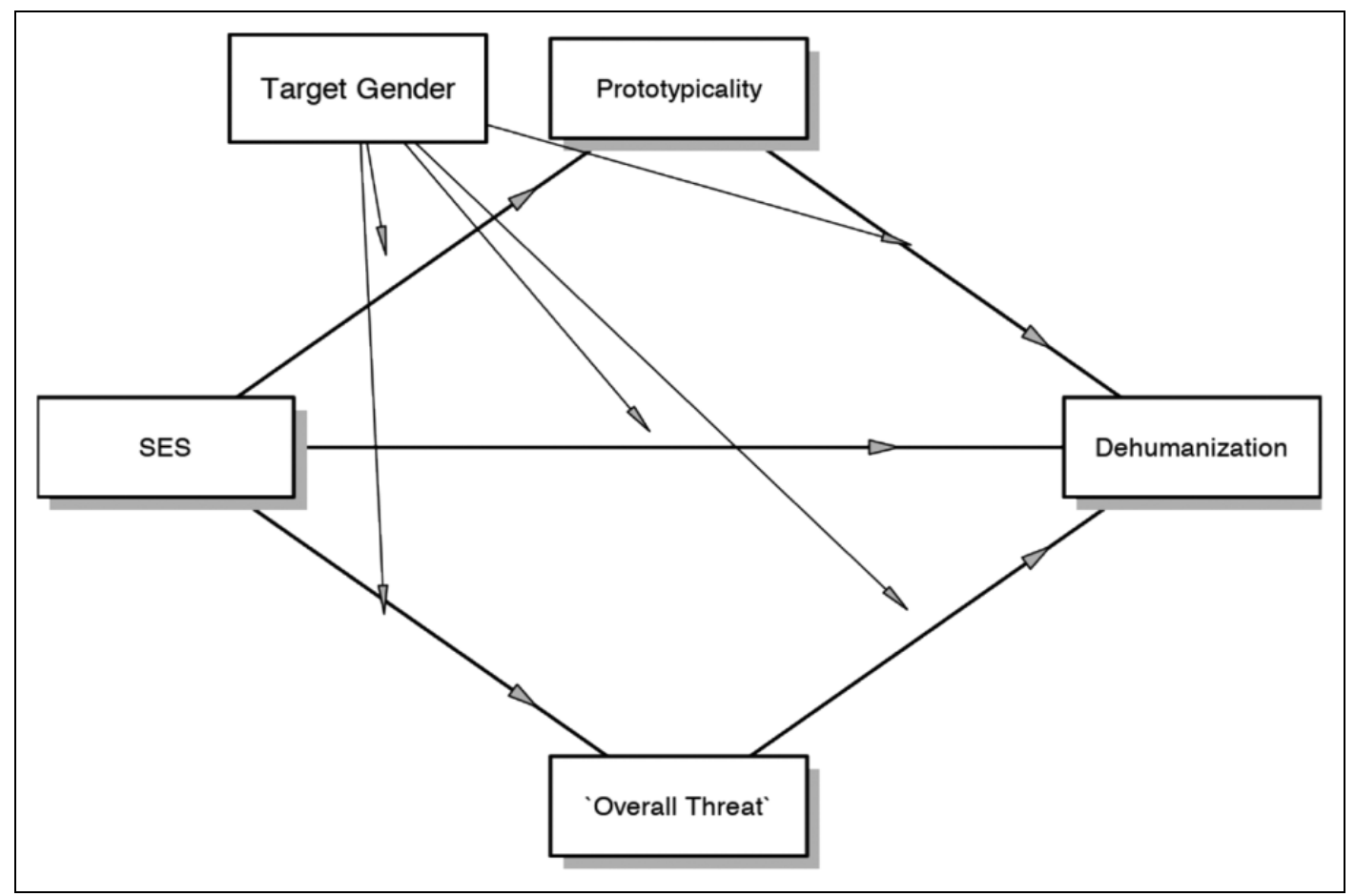

Figure 3. Schematic diagram describing moderated mediation model conducted.

participants. Prototypicality accounted for the link between norm violation and dehumanized perception, but only when the target was female, further highlighting the role of target gender (Cikara et al., 2011; Fiske, 2013) in predicting dehumanization.

\section{General Discussion}

Across two studies, we demonstrate that the influence of SES on dehumanization depends specifically on one's contact likelihood with targets (Study 1) and the perceived normativity of a targets' behavior (Study 2). Our findings contribute to the literature by applying the SCM in a non-WEIRD culture. By focusing on the role of perceiver SES, we further extend the model's applicability to cross-SES perceptions. In addition, we highlight the roles of contact likelihood (Allport, 1954) and prototypicality (Van Kleef et al., 2011) as psychological mechanisms that account for why SES predicts dehumanized perceptions.

In Study 1, upper SES respondents were more likely to deprive beggars of cognitive attributes due to their reduced contact likelihood. One possible explanation for reduced contact is the mode of transportation chosen by members of each social class. In urban India, cross-class contact mostly occurs when people traverse the city streets. However, upper SES individuals often travel via private vehicles (e.g., cars) - meaning that the upper SES people tend to be physically divided from all others, thereby reducing contact likelihood (Kundu \& Bhattacharya, 2018; NFHS-4, 2017). In contrast, those from lower SES backgrounds tend to travel by bicycle, foot, or local trains, increasing their contact likelihood with beggars (Iqbal,
2013). These everyday choices exacerbate physical divides between social classes and may facilitate dehumanized perceptions of societal outcasts.

Furthermore, in a society with limited upward mobility and a high risk of downward social mobility, those from lower SES backgrounds are under constant threat to lose their livelihoodthereby leading to homelessness (Driver \& Driver, 1987; Iverson et al., 2017; Krishna, 2017; World Inequality Lab, 2018). Hence, lower SES people may also be more humanizing toward beggars due to the genuine possibility of a shared fate (Butalia, 2013; Dhilon, 2015; Kraus \& Stephen, 2012).

In Study 2, norm violators were viewed as less human and less prototypical, but prototypicality explained why norm violators were dehumanized only when the target was female. Our findings align with past research on the SCM. Due to culturally informed stereotypes about the essentialist nature of warmth in a woman (Eckes, 2002; Huddy \& Terkildsen, 1993), women are categorized as high warmth by default and expected to adhere to norms (Fiske et al., 2002). However, women who step out of their traditional subservient roles (e.g., working women) are either perceived as competent but cold (akin to a robot) or viewed as sex objects low on warmth and competence (Cikara et al., 2011; Fiske, 2013), perhaps more so in societies with severe patriarchal traditions (Chakravarti, 1993; Titzmann, 2011). As such, norm-violating women were seen as less prototypical of their group and hence dehumanized.

Another factor that could be a possible explanation for our observed patterns of dehumanized perception is liking (or dislike for certain types of targets). However, it is an unlikely explanation considering the mean scores on the human 
attributes scales are below midpoint, and we also find similar results for overt dehumanization in Study 2. Further research is required to disentangle the influence of liking from dehumanized perceptions.

Future work should also consider empirically unpacking whether actual contact, or norm adherence, could act as alleviating factors for dehumanization. While we focus on the mechanisms that exacerbate dehumanized perceptions, more work is needed to address how stigmatized groups could be seen with greater empathy and understanding (Fiske, 2013).

Furthermore, it would be theoretically meaningful to compare between societies that have different understandings of class structures. We examined dehumanization in the urban Indian context where unequal distribution of wealth has become the norm (Krishna, 2017). Perhaps people from societies that strive for equality may display a different pattern of social cognition, where SES-based dehumanization is less common as a function of flat power structures and social contact.

In summary, we elucidate the conditions under which dehumanized perceptions occur in cross-class interactions. Our findings align with classic theorizing in social psychology (Allport, 1954; Fiske et al., 2007; Harris \& Fiske, 2011) while testing the rigor of such models in a non-WEIRD sample within the frame of SES. We hence contribute to two rapidly growing areas of empirical work, social class (Kraus \& Stephens, 2012) and norm violations (Van Kleef et.al, 2011), and provide evidence from a unique cultural context that is especially suitable for the present research.

\section{Author Contributions}

Priyanka Khatry (PK) and Kunalan Manokara (KM) contributed equally to this work. PK and KM designed the study with the guidance of Lasana Harris (LH). PK collected data, and analysis was conducted by KM. All three authors were involved in the writing of the paper.

\section{Declaration of Conflicting Interests}

The author(s) declared no potential conflicts of interest with respect to the research, authorship, and/or publication of this article.

\section{Funding}

The author(s) received no financial support for the research, authorship, and/or publication of this article.

\section{ORCID iD}

Priyanka Khatry (D) https://orcid.org/0000-0003-3094-3213

Kunalan Manokara (D) https://orcid.org/0000-0002-7801-9292

\section{Supplemental Material}

The supplemental material for this article is available online.

\section{Notes}

1. Stimuli version was not significantly predictive of affective attributes, $F(1,227)=1.03, p_{\text {Bonferroni }}=.936, \eta_{\mathrm{p}}^{2}=.005$, cognitive attributes, $F(1,227)=4.07, p_{\text {Bonferroni }}=.135, \eta_{\mathrm{p}}^{2}=.018$, nor contact likelihood, $F(1,227)=0.10, p_{\text {Bonferroni }}>.999, \eta_{\mathrm{p}}^{2}<.001$.
2. As part of the first author's thesis, we also included questions indicative of disgust, empathy, interaction behavior, and identification of target (see Supplement A).

3. In both studies, we log-transformed monthly income to account for positive skewness (Study 1: index $=4.26$, Study 2: index $=7.80$ ), but the transformed variable was negatively skewed (Study 1: index $=-2.05$, Study 2: index $=-2.37$ ).

4. Because the item measuring familiarity did not load onto either dimension of the human attributes inventory, we explored whether familiarity would mediate the effect of social class on cognitive attributes. This indirect effect was nonsignificant, $b=-.02$, $S E=.02,95 \% \mathrm{CI}=[-.06, .01], z=1.29, p=.197$.

5. Together with demographics, we included exploratory measures (see Supplement B).

6. Target social class did not significantly interact with any other factor in our models. For transparency, we conducted identical mediation analyses, contrasting behavior within each manipulated social class condition. A similar pattern of results was found across conditions (see Supplement B).

\section{References}

Adler, N. E., Boyce, T., Chesney, M. A., Cohen, S., Folkman, S., Kahn, R. L., \& Syme, S. L. (1994). Socioeconomic status and health: The challenge of the gradient. American Psychologist, 49(1), 15-24. https://doi.org/10.1037/0003-066X.49.1.15

Adler, N. E., \& Stewart, J., \& the Psychosocial Working Group. (2007). The MacArthur scale of subjective social status. MacArthur Research Network on SES \& Health. https://macses. ucsf.edu/research/psychosocial/subjective.php

Allport, G. W. (1954). The nature of prejudice. Addison-Wesley.

Bastian, B., Laham, S., Wilson, S., Haslam, N., \& Koval, P. (2011). Blaming, praising, and protecting our humanity: The implications of everyday dehumanization for judgments of moral status. British Journal of Social Psychology, 50(3), 469-483. https://doi.org/10. 1348/014466610X521383

Bhatia, S. (2018). Decolonizing psychology. Oxford University Press. Bourdieu, P. (1984). Distinction a social critique of the judgement of taste. Harvard University Press.

Budhwar, P., \& Varma, A. (2011). Doing business in India: Building research-based practice (1st ed.). Routledge.

Butalia, U. (2013). India's elites have a ferocious sense of entitlement [Weblog]. Retrieved February 2, 2020, from https://newint.org/fea tures/2013/01/01/india-elite-sense-of-entitlement

Chakravarti, U. (1993). Conceptualising brahmanical patriarchy in early India: Gender, caste, class and state. Economic and Political Weekly, 28(14), 579-585. http://www.jstor.org/stable/4399556?ori gin=JSTOR-pdf

Cialdini, B., \& Trost, R. (1998). Social influence: Social norms, conformity and compliance. In D. T. Gilbert, S. T. Fiske, \& G. Lindzey (Eds.), The handbook of social psychology (pp. 151-192). McGraw-Hill.

Cikara, M., Eberhardt, J. L., \& Fiske, S. T. (2011). From agents to objects: Sexist attitudes and neural responses to sexualized targets. Journal of Cognitive Neuroscience, 23(3), 540-551. https://doi. org/10.1162\%2Fjocn.2010.21497 
Cohen, D., Shin, F., Liu, X., Ondish, P., \& Kraus, M. W. (2017). Defining social class across time and between groups. Personality and Social Psychology Bulletin, 43(11), 1530-1545. https://doi. org/10.1177/0146167217721174

Côté, S., Kraus, M. W., Carpenter, N., Piff, P. K., Beermann, U., \& Keltner, D. (2017). Social affiliation in same-class and crossclass interactions. Journal of Experimental Psychology: General, 146(2), 269-285. https://doi.org/10.1037/xge0000258

Cuddy, A. J. C., Fiske, S. T., \& Glick, P. (2008). Warmth and competence as universal dimensions of social perception: The stereotype content model and the BIAS map. In M. P. Zanna (Ed.), Advances in experimental social psychology: Vol. 40 (pp. 61-149). Elsevier Academic Press. https://doi.org/10.1016/S0065-2601(07)00002-0

Dahlberg, J. (1996, February 29). In India, more women are wearing the pants [Weblog]. Retrieved January 2, 2020, from https://www. latimes.com/archives/la-xpm-1996-02-29-1s-41230-story.html

Danbold, F., \& Huo, Y. J. (2015). No longer “all-American”? Whites' defensive reactions to their numerical decline. Social Psychological and Personality Science, 6(2), 210-218. https://doi.org/10. $1177 / 1948550614546355$

Dasgupta, I., \& Pal, S. (2018). Touch thee not: Group conflict, caste power, and untouchability in rural India (IZA discussion papers No. 12016). Institute of Labor Economics (IZA). https://www. econstor.eu/bitstream/10419/193310/1/dp12016.pdf

Dhillon, A. (2015). For wealthy Indians, generosity is yet to become a way of life [Weblog]. Retrieved February 2, 2020, from https:// www.thenational.ae/opinion/for-wealthy-indians-generosity-isyet-to-become-a-way-of-life-1.36023

Driver, E., \& Driver, A. (1987). Social class in urban Indian: Essays on cognitions and structures. EJ Brill Leiden.

Eckes, T. (2002). Paternalistic and envious gender stereotypes: Testing predictions from the stereotype content model. Sex Roles, 47(1), 99-114. https://doi.org/10.1023/A:1021020920715

Faul, F., Erdfelder, E., Buchner, A., \& Lang, A.-G. (2009). Statistical power analyses using $\mathrm{G}^{*}$ Power 3.1: Tests for correlation and regression analyses. Behavior Research Methods, 41(1), 1149-1160. https://doi.org/10.3758/BRM.41.4.1149

Fine, D., Manyika, J., Sjatil, P., Tacke, T., Tadjeddine, K., \& Desmond, M. (2019). Inequality: A persisting challenge and its implications. McKinsey Global Institute. https://www.mckinsey. com/ /media/McKinsey/Industries/Public\%20and\%20Social $\% 20$ Sector/Our\%20Insights/Inequality $\% 20 \mathrm{~A} \% 20$ persisting $\% 20$ challenge $\% 20$ and $\% 20$ its $\% 20$ implications/Inequality-A-persistingchallenge-and-its-implications.pdf

Fiske, S. T. (2013). Varieties of (de)humanization: Divided by competition and status. In S. J. Gervais (Ed.), Objectification and dehumanization (pp. 53-72). Springer.

Fiske, S. T., Cuddy, A. J. C., \& Glick, P. (2007). Universal dimensions of social cognition: Warmth and competence. Trends Cognition, 11(2), 77-83. https://doi.org/10.1016/j.tics.2006.11.005

Fiske, S. T., Cuddy, A. J. C., Glick, P., \& Xu, J. (2002). A model of (often mixed) stereotype content: Competence and warmth respectively follow from perceived status and competition. Journal of Personality and Social Psychology, 82(6), 878-902. https://doi. org/10.1037/0022-3514.82.6.878
Freitas, K. (2006). The Indian caste system as a means of contract enforcement [Working paper]. Northwestern University. https:// web.stanford.edu/ avner/Greif_228_2007/Freitas,\%20Kripa. \%202006.\%20The\%20Indian\%20Caste\%20System.pdf

Gallo, L. C., \& Matthews, K. A. (2003). Understanding the association between socioeconomic status and physical health: Do negative emotions play a role? Psychological Bulletin, 129(1), 10-51. https://doi.org/10.1037/0033-2909.129.1.10

Gallucci, M. (2019). GAMLj: General analyses for linear models [jamovi module]. https:/gamlj.github.io/

Gelles, R. (2011). Fair and lovely: Standards of beauty, globalization, and the modern Indian woman (Independent study project [ISP] collection. Paper 1145) https://www.semanticscholar.org/paper/ Fair-and-Lovely\%3A-Standards-of-Beauty\%2C-and-the-WomanGelles/c3d1450b41d729157e5f1585a19eb9f5c20681b2

Glick, P., \& Fiske, S. (1996). The ambivalent sexism inventory: Differentiating hostile and benevolent sexism. Journal of Personality and Social Psychology, 70(3), 491-512. https://doi.org/10. 1037/0022-3514.70.3.491

Gray, H., Gray, K., \& Wegner, D. (2007). Dimensions of mind perception. Science, 315(5812), 619. https://doi.org/10.1126/SCIENCE. 1134475

Harris, L. T. (2017). Visible people, invisible minds: How and why the brain flexibly perceives humanity. MIT Press.

Harris, L. T., \& Fiske, S. T. (2006). Dehumanizing the lowest of the low: Neuroimaging responses to extreme out-groups. Psychological Science, 17(10), 847-853. https://doi.org/10.1111/j.14679280.2006.01793.x

Harris, L. T., \& Fiske, S. T. (2007). Social groups that elicit disgust are differentially processed in mPFC. Social Cognitive and Affective Neuroscience, 2(1), 45-51. https://doi.org/10.1093\%2Fscan $\% 2$ Fns1037

Harris, L. T., \& Fiske, S. T. (2009). Social neuroscience evidence for dehumanised perception. European Review of Social Psychology, 20(1), 192-231. https://doi.org/10.1080/10463280902954988

Harris, L. T., \& Fiske, S. T. (2011). Dehumanized perception: A psychological means to facilitate atrocities, torture, and genocide? Zeitschriftfur Psychologie, 219(3), 175-181. https://doi.org/10. $1027 \% 2 \mathrm{~F} 2151-2604 \% 2 \mathrm{Fa} 000065$

Haslam, N. (2006). Dehumanization: An integrative review. Personality and Social Psychology Review, 10(3), 252-264. https://doi.org/ $10.1207 /$ s15327957pspr1003_4

Haslam, N., \& Loughnan, S. (2014). Dehumanization and infrahumanization. The Annual Review of Psychology, 65(1), 399-423. https://doi.org/10.1146/annurev-psych-010213-115045

Henrich, J., Heine, S. J., \& Norenzayan, A. (2010). Most people are not WEIRD. Nature, 466(7302), 29-29.

Henrich, J., Heine, S. J., \& Norenzayan, A. (2010). The weirdest people in the world? Behavioral and Brain Sciences, 33(2-3), 61-83.

Huddy, L., \& Terkildsen, N. (1993). Gender stereotypes and the perception of male and female candidates. American Journal of Political Science, 37(1), 119-147. https://doi.org/10.2307/2111526 Iqbal, R. (2013). Begging: A growing menace in India. International Journal of Advanced Research in Management and Social Sciences, 2(8), 37-62. http://www.garph.co.uk/IJARMSS/ Aug2013/4.pdf 
Iversen, V., Krishna, A., \& Sen, K. (2017). Rags to riches? Intergenerational occupational mobility in India. Economic and Political Weekly, 52(44), 107-114. https://pdfs.semanticscholar.org/6f23/ dc657856c3eaf8583f48f2b37a111ef89501.pdf

Kalpagam, U. (2008). Marriage norms, choice and aspirations of rural women. Economic and Political Weekly, 43(21), 53-63. http://www.rrcee.net/wp-content/uploads/2016/03/254_Marriage_ Norms_Choice_and_Aspirations_of_Rural_Women.pdf

Kraus, M., \& Mendes, W. (2014). Sartorial symbols of social class elicit class-consistent behavioral and physiological responses: A dyadic approach. Journal of Personality and Social Psychology, 143(6), 2330-2340. http://doi.org/10.1037/xge0000023

Kraus, M., Piff, P., Mendoza-Denton, R., Rheinschmidt, M., \& Keltner, D. (2012). Social class, solipsism, and contextualism: How the rich are different from the poor. Psychological Review, 119(3), 546-572. https://www.krauslab.com/SESpsychreview. 2012.pdf

Kraus, M., \& Stephens, N. (2012). A road map for an emerging psychology of social class. Social and Personality Psychology Compass, 6(9), 642-656. http://www.krauslab.com/Kraus\&Ste phens.Compass.2012.pdf

Krendl, A. C., Heatherton, T. F., \& Kensinger, E. A. (2009). Aging minds and twisting attitudes: An fMRI investigation of age differences in inhibiting prejudice. Psychology and Aging, 24(3), 530-541. https://doi.org/10.1037/a0016065

Krendl, A. C., Macrae, C. N., Kelley, W. M., Fugelsang, J. A., \& Heatherton, T. F. (2006). The good, the bad, and the ugly: An fMRI investigation of the functional anatomic correlates of stigma. Social Neuroscience, 1(1), 5-15. https://doi.org/10.1080/ 17470910600670579

Krishna, A. (2017). The broken ladder: The paradox and potential of India's one-billion (1st ed.). Cambridge University Press.

Kundu, T., \& Bhattacharya, P. (2018). India runs on two wheels and animal carts, data shows. Retrieved February 2, 2020, from https:/www.livemint.com/Auto/N3Ixh0Mv3eu2vWfzeiRw3N/ India-runs-on-two-wheels-and-animal-carts-data-shows.html

Kurzban, R., \& Leary, M. R. (2001). Evolutionary origins of stigmatization: The functions of social exclusion. Psychological Bulletin, 127(2), 187-208. https://doi.org/10.1037/0033-2909.127.2.187

Loughnan, S., Haslam, N., Sutton, R. M., \& Spencer, B. (2014). Dehumanization and social class: Animality in the stereotypes of "white trash," "chavs," and "bogans." Social Psychology, 45(1), 54-61. https://doi.org/10.1027/1864-9335/a000159

Ministry of Health and Family Welfare, Government of India. (2017). National family health survey (NFHS-4) 2015-16. International Institute for Population Sciences, 1(1), 1-572. http://rchiips.org/ nfhs/NFHS-4Reports/India.pdf

Montaut, A. (2010). English in India. In C. Shreesh \& I. S. Hasnain (Eds.), Problematizing language studies, cultural, theoretical and applied perspectives. Essays in honor of Rama Kant Agnihotri (pp. 83-116) Aakar Books. https://www.academia.edu/10026268/Eng lish_in_India_and_the_role_of_the_elite_in_the_national_proj ect_the_elite_in_the_national_project

Mosse, D. (2019). The modernity of caste and the market economy. Modern Asian Studies, 1-47. https://doi.org/10.1017/S0026749X 19000039
Mount, L. (2017). Saris and contemporary Indian womanhood: How middle-SES women navigate the tradition/modernity split. Contemporary South Asia, 25(2), 167-181. https://doi.org/10. 1080/09584935.2017.1321617

Nelson, L. D., Simmons, J., \& Simonsohn, U. (2018). Psychology's renaissance. Annual Review of Psychology, 69(1), 511-534. https://doi.org/10.1146/annurev-psych-122216-011836

Ohbuchi, K., Tamura, T., Quigley, B. M., Tedeschi, J. T., Madi, N., Bond, M. H., \& Mummendey, A. (2004). Anger, blame, and dimensions of perceived norm violations: Culture, gender, and relationships. Journal of Applied Social Psychology, 34(8). https://doi.org/10.1111/j.1559-1816.2004.tb02788.x

Pettigrew, T. F., \& Tropp, L. R. (2006). A meta-analytic test of intergroup contact theory. Journal of Personality and Social Psychology, 90(5), 751-783. https://doi.org/10.1037/0022-3514.90.5.751

Piff, P. K., Kraus, M. K., \& Keltner, D. (2018). Unpacking the inequality paradox: The psychological roots of inequality and social class. In J. M. Olson (Ed.), Advances in Experimental Social Psychology, 57(1), 53-124. https://doi.org/10.1016/bs.aesp.2017. 10.002

Piff, P. K., Kraus, M. W., Côté, S., Cheng, B. H., \& Keltner, D. (2010). Having less, giving more: The influence of social class on prosocial behavior. Journal of Personality and Social Psychology, 99(5), 771-784. https://doi.org/10.1037/a0020092

Piff, P. K., Stancato, D. M., Côté, S., Mendoza-Denton, R., \& Keltner, D. (2012). Higher social class predicts increased unethical behavior. Proceedings of the National Academy of Sciences of the United States of America, 109(11), 4086-4091. https://doi.org/ 10.1073/pnas. 1118373109

Sainz, M., Martínez, R., Moya, M., \& Rodríguez-Bailón, R. (2019). Animalizing the disadvantaged, mechanizing the wealthy: The convergence of socio-economic status and attribution of humanity. International Journal of Psychology, 54(64), 423-430. https://doi. org/10.1002/ijop.12485

Sandhu, A. (2015). Indian fashion: tradition, innovation, style (1st ed.). Bloomsbury Academic.

Singh, M. (2016). Depictions of empowerment? How Indian women are represented in vogue India and India today woman (1st ed.). University of Minnesota.

Spence, J. T., \& Hahn, E. D. (1997). The attitudes toward women scale and attitude change in college students. Psychology of Women Quarterly, 21(1), 17-34. https://doi.org/10.1111/j.1471-6402. 1997.tb00098.x

Stamkou, E., van Kleef, G. A., Homan, A. C., \& Galinsky, A. D. (2016). How norm violations shape social hierarchies: Those who stand on top block norm-violators from rising up. Group Processes \& Intergroup Relations, 19(5), 608-629. https://doi.org/10. $1177 \%$ F 1368430216641305

Stephan, C. W., Stephan, W. G., Demitrakis, K. M., Yamada, A. M., \& Clason, D. L. (2000). Women's attitudes toward men: An integrated threat theory approach. Psychology of Women Quarterly, 24(1), 63-73. https://doi.org/10.1111/j.1471-6402.2000.tb01022.x

Titzmann, F. M. (2011). Matchmaking 2.0 the representation of women and female agency in the Indian online matrimonial market. Internationales Asienforum, 42(3-4), 239-256. https://doi. org/10.11588/iaf.2011.42.153 
United Nations. (2016, January 28). Report of the special rapporteur on minority issues. Human Rights Council. Retrieved February 19, 2020, from https://www.ohchr.org/EN/HRBodies/HRC/Regu larSessions/Session31/_layouts/15/WopiFrame.aspx?sourcedoc $=$ / EN/HRBodies/HRC/RegularSessions/Session31/Documents/A_ HRC_31_56_en.doc\&action=default\&DefaultItemOpen $=1$

Van Kleef, G. A., Homan, A. C., Finkenauer, C., Gündemir, S., \& Stamkou, E. (2011). Breaking the rules to rise to power: How norm violators gain power in the eyes of others. Social Psychological and Personality Science, 2(5), 500-507. https://doi.org/10.1177/1948550611398416

Van Kleef, G. A., Wanders, F., Stamkou, E., \& Homan, A. (2015). The social dynamics of breaking the rules: Antecedents and consequences of norm-violating behavior. Current Opinion in Psychol$o g y, 6(1), 25-31$. https://doi.org/10.1016/j.copsyc.2015.03.013

Wang, X., \& Krumhuber, E. G. (2017). The love of money results in objectification. British Journal of Social Psychology, 56(2), 354-372. https://doi.org/10.1111/bjso. 12158

Westfall, J. (2015). PANGEA: Power analysis for general ANOVA designs [Unpublished manuscript]. http://jakewestfall.org/publica tions/pangea.pdf
Williams, K. D. (1997). Social ostracism. In R. M. Kowalski (Ed.), The Plenum series in social/clinical psychology. Aversive interpersonal behaviors (pp. 133-170). Plenum Press. https://doi.org/10. 1007/978-1-4757-9354-3_7

World Inequality Lab. (2018). World inequality report. Retrieved February 3, 2020, from https://wir2018.wid.world/download.html

\section{Author Biographies}

Priyanka Khatry completed her MSc in social cognition at UCL. She is currently working as a freelance researcher and strategic consultant in Mumbai (India) and pursuing an MA social anthropology at SOAS University of London.

Kunalan Manokara is a doctoral researcher in social psychology at the University of Amsterdam, the Netherlands.

Lasana T. Harris is an associate professor in experimental psychology at UCL. He is also the principal investigator of the Boundaries of Social Cognition (BSC) lab. 